\title{
Use of Simulation for Waste Management and Reverse Material Flow
}

\author{
Nikoleta Mikušová' ${ }^{*}$, Eva Tomková', Miroslav Dovica², Borna Debelic³, \\ Ana Peric-Hadzic ${ }^{3}$, Jozef Zajac ${ }^{4}$ \\ 1 Faculty of Mining, Ecology, Process Control and Geotechnology, Technical University of Košice, Letná 9, \\ 04200 Košice, Slovakia \\ 2 Faculty of Mechanical Engineering, Technical University of Košice, Letná 9, 04200 Košice, Slovakia \\ 3 Faculty of Maritime Studies, University of Rijeka, Studentska ulica 2, 51000 Rijeka, Croatia \\ ${ }^{4}$ Faculty of Manufacturing Technologies, Technical University of Košice, Bayerova 1, 08001 Prešov, Slovakia \\ * Corresponding author's e-mail: nikoleta.mikusova@tuke.sk
}

\begin{abstract}
The wastes which infiltrate into the environment are created from unexpended materials and products. The environment can manage a great amount of waste, but this process requires time. Nature always attempts to achieve the balance. However, degradation of some materials in nature takes about 1000 years, which is a very long period of time in terms of the length of a human life, also in view of the rising trend of wastes generation. The need for appropriate waste management is steadily rising, as does the production of wastes and our living standards. Incorrect waste management has a negative impact on all components of the environment. Waste management, their processing and recycling additionally contribute to human health protection and preservation of a healthy environment. Another benefit is in the form of raw materials extraction, the global supplies of which are constantly reducing. One of the possible ways of effective waste management is improving environmental awareness but the science brings different ways of solution, for example in connection with waste management and simulation of wastes flow. The paper presents one of this ways by help with the creation of centralized collection point of wastes using a universal model which is usable for different countries with the problem of wastes and waste management.
\end{abstract}

Keywords: waste, simulation, model, centralized collection point

\section{INTRODUCTION}

With an exponential growth of industry and production, the amount of waste increases as well, and at the same time, its composition is also changing, influenced by life modernization. The area of the environment is a very desolate field. At the moment, it is necessary to increase the level of attention in order to leave the environment healthy for the future generation. Production of wastes and their subsequent storage influence the environment excessively. The majority of the wastes can be processed, for example by recycling, repairing or other technologies. This requires a change in the environmental thinking and increasing the environmental awareness. One of the ways to focus on improving the environment is to monitor reverse material flows and realize implement effective waste management.

\section{PROBLEM DEFINITION}

Generation of wastes is an integral part of human existence. With the development of industrial production, the human society is producing more and more diversified wastes. The production of wastes and their subsequent accumulation does not only change the environment but it also presents a potential risk of contamination of water resources, air and land [1]. On the other hand, wastes contain valuable reusable energy sources 
and raw materials. A set of activities oriented at prevention and reduction of wastes generation, reduction of their impact on the environment and treatment with wastes is considered in the waste management [11]. The aim of the waste management is to prevent the generation of wastes and to limit their creation, above all by:

- development of the technologies saving natural resources,

- development of suitable methods for disposal of dangerous materials in wastes,

- evaluating wastes by recycling, reuse or other processes with the aim to obtain secondary raw materials,

- using wastes as a source of energy, if material recovery is not possible,

- disposal of wastes by the way which does not endanger human health and the environment.

Waste management must adapt to constant spatial variability, change of products and technologies, as well as new and improved legislation. Requirements for waste management are presented by the monitoring of:

- quantity of wastes

- the composition of wastes also in terms of commodities of wastes,

- collection of wastes,

- recycling, reuse or disposal of wastes.

In order to meet these requirements, an integrated system of waste management, called Integrated Sustainable Waste Management, was prepared. The term sustainable means a system suitable for the local area, with technical, social, economic, financial, enterprise conditions and the conditions of the environmental perspective, which is able to support the requirements of the law at the required time. The notion integrated means a system using a series of reciprocal relations of collection and treatment ways and different level of locality. This system enables to use the relation of urbanism and the system of waste management and also to carry out activities for entrepreneurs. The principle of the integrated sustainable waste management consists of the technical-operational principle, the principle of the environment, financial principle, socio-economic principle, technical-operational principle, institutional and administrative principle, political and legal principle. The great emphasis in this system and the creation of models for this system is placed on the trend analysis of the area and program of minimizing its costs [4].
Achievement of a successful waste management is based on the activities of waste management necessary to perform, in the order from the first to the last. The first activity is to prevent the generation of wastes, the second activity is to reuse materials, the third activity is material recycling, the fourth activity is using the material for energy recovery and the fifth activity is liquidation and disposal of materials which is the least convenient way.

On the part of ways of wastes management, the most used solution is dumping of wastes, which is the worst approach in the hierarchy of wastes treatment. By the statistical comparison of the European Union, more than 4 mils. $t$ of wastes are dumped per year [3]. This way of wastes treatment is environmentally and legislatively unacceptable and it is necessary to eliminate this way of wastes treatment. The aim of the European Union is primarily to reduce the negative environmental impacts of wastes on the human health and the environment (Figure 1.). It is necessary to precisely meet the hierarchy of the waste management and wastes treatment and enforce the responsibility for wastes in the sense the polluter fees.

For the waste management program and monitoring of reverse material flow, it is necessary to implement the following steps: enforce more responsibility on producers and also their care of products after end of the lifecycle, increase the collection of recyclable wastes, increase the amount of recycled products, create a system of support of goods from recycled materials, financially support the reuse, improve the information system about the wastes, about the ways of collection, reuse, recycling, increase the control of compliance with the waste management. From the total quantity of wastes, including the wastes imported to the countries of European Union, $36.2 \%$ of wastes were materially recycled, $10.2 \%$ of wastes were reverse processed, $4.7 \%$ were used energetically, $1.5 \%$ were burnt, while $47.4 \%$ of wastes were dumped [3].

On the basis of the above-mentioned statistics, it is possible to state that the greatest problem of wastes is landfilling and elimination of landfills. One of the effective tools for the solution of this problem is to increase the environmental awareness of people, but the best way is the process of wastes collection and their subsequent effective processing with the aim to obtain reusable raw materials and products [13]. Collection of 


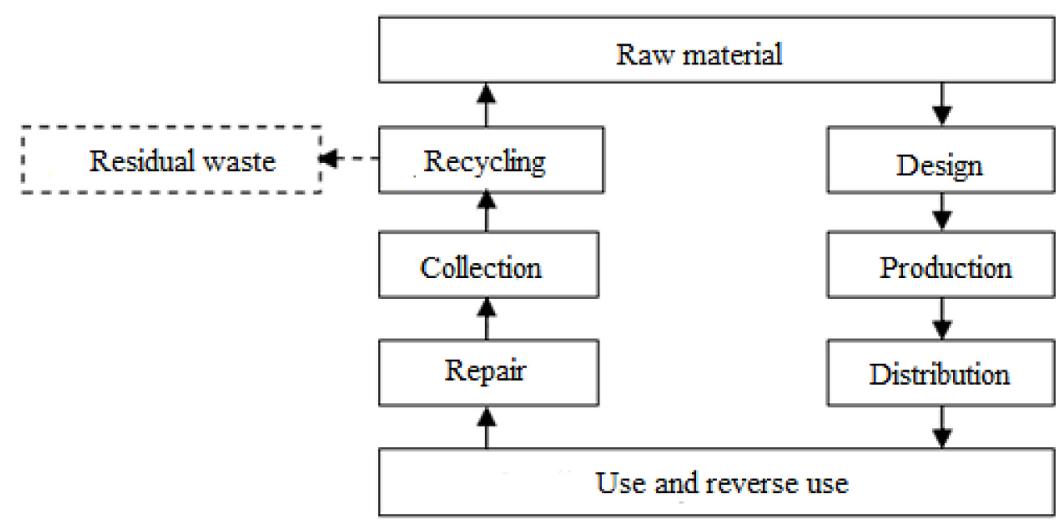

Fig. 1. System of reverse waste management of EU [3]

wastes presents a very important part of the waste management and logistics of waste management. Management of waste collection is formed by a sequence of operations that occur at the waste producer and end at the point of processing, recycling or dumping places [7].

At present, in addition to the monitoring of wastes flow, reverse flow of materials, statistical indicators, simulation and modelling of the flow of wastes are important tools. These tools are able to determine for example the optimal route for transport of wastes, or the collection points for the same commodities of waste with an emphasis on the environment and economic indicators on the basis of input data, amount of wastes, sources of processing, etc..

\section{SIMULATION}

Simulation presents a formation of an effective or a real system with its partial processes that are directed by a model $[5,9]$. The experiments with this simulation model are based on input data, which can be modified and in this way it is possible to improve the simulated conditions and apply under actual conditions [10]. It is possible to divide the whole simulation project into 4 parts, namely definition of the problem, creation of a model and its testing, experiments and finalization of the project and its presentation. Simulation enables to solve analytically unsolvable tasks, search system dynamics, time and spatial comparisons, detect new facts, support decisionmaking at different levels of decision-making, as well as improve the system and cost savings in various areas. In terms of research technology, the essence of modelling is to replace the research system with a model. The aim is to obtain the information about the research system, with the help of the model. This means that a model in which the research system forms a model system is created. The simulation model presents a simplified virtual or real unit which contains all the partial processes of the system. It describes the behaviour of elements in the simulation program. Simulation methods differ from other methods by the way of obtaining the solutions that were observed from the running of the model (program). This monitoring is often included in a separate simulation model. This model is able to provide the results on the basis of the information obtained from changes in the state during the model time.

Simulation helps to solve very complex systems that cannot be solved by analytical methods, or where the use of an analytical solution would be very simplistic.

With the help of simulation, it is possible to verify the results obtained with other methods in terms of dynamic and stochastic effects. Simulation enables to study the system behaviour in real, accelerated or slow time. The experience from simulation models creation can lead to suggestions for improving management or structure. Creation of a simulation model is not possible without a thorough analysis of the system under review, which can reveal significant reserves at the beginning of the project. Simulation provides a complex view of the studied problem and allows its multi-criteria analysis. Using the model, it is possible to monitor different parameters of the system and also the connection of subsystems. Monitoring of activities of the simulation model aims at better understanding of the real system. By changing one parameter of the system, it is possible to monitor its effect on the system behaviour, as well as on other variables. With the help of simulation, it is possible thoroughly to verify 
various variants of the solution. This helps to minimize the risks of erroneous decisions or prepare the variants for unexpected events $[6,8,12]$.

\section{EXAMPLE OF SIMULATION USE FOR THE CREATION OF CENTRALIZED COLLECTION POINTS FOR WASTES}

One of the possible ways to create an effective system of waste management and to implement reverse material flow is a consistent realization of wastes collection. An alternative for solution of wastes collection is the creation of centralized collection points (CCP) of wastes. In terms of waste management, CCP of wastes have to realize the primary sorting of wastes in the form of initial inspection, select wastes, which are directly uses, carry out other sorting of wastes by the types of materials, implement the selected methods of recycling (in the case if the CCP deals with this activity) of wastes and their parts and materials, or transport wastes to the points of further processing with the aim to obtain secondary raw materials. Within the frame of connecting simulation and waste management, a primary model of the CCP for the area of Slovakia was created, which is applicable to the conditions of other EU countries after certain modification.

The structure and system of the simulation model are presented by two basic types of flows, namely flow of information and flow of material (used tires). It is necessary to emphasize that these types of flows are extensive and it is possible to divide them to subtypes. Moreover, the flows are connected and they are on three basic structures of the model:

- $1^{\text {st }}$ structure - internal - flow of materials and information within the frame of one region,

- $2^{\text {nd }}$ structure - external I. - flow of materials and information among centralized collection points,
- $3^{\text {rd }}$ structure - external II. - flow of materials and information among centralized collection points and processing enterprises.

For the extensity of the real system, the EXTEND program was selected for the simulation language. This program offers the possibility performing of a wide range of simulations, such as development of own libraries or processes. This program creates an area for the formation of dynamic models of real processes in various fields. The models created by the blocks of this program, offer to examine complex processes, monitor their common dependence and also change of their parameters with the help of optimal solution. Using this program, it is possible to create block schemes of processes as well as devices and blocks describe part of process or device and they are connected by inputs and outputs.

- The model speculated with three basic input block schemes (Fig. cc) and these were divided into these partial block schemes:

- The block scheme I with the first part of waste management - input inspection (controlling of wastes) (Figure 2)

- The 2block II with the application of the wastes sorting process (Figure 3.)

- Block scheme III. The way "material/waste" perform the centralized collection point and processing process with outputs (Figure 4.)

At the same time, it is necessary to emphasize that it was monitoring the total number of wastes per month in the centralized collection point, number of orders for direct use, number of order for next processing, and the number of customers by the information flow and the total amount of wastes, amount of transported wastes to the centralized collection point, amount of distributed material, amount of repaired, as well as reuse materials by the material flow.

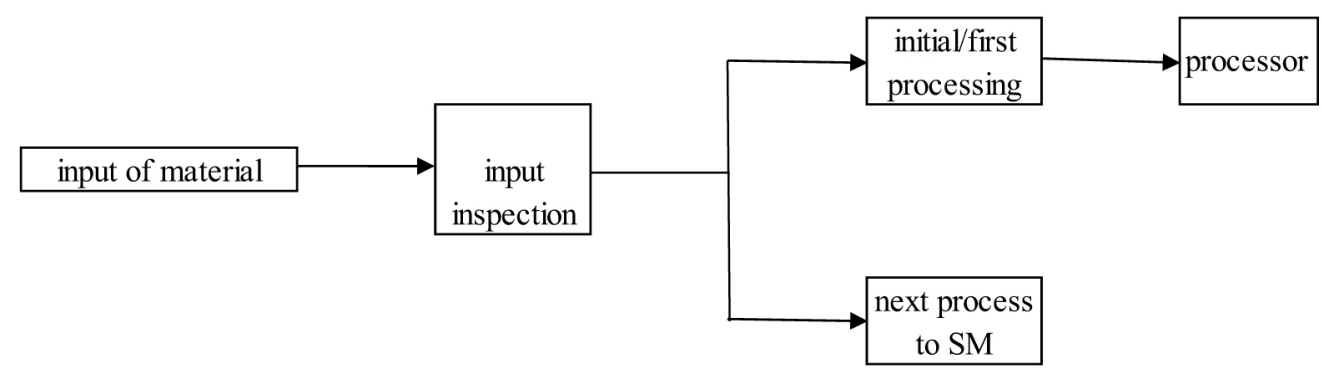

Fig. 2. Block scheme of the input process "material/waste" to the centralized collection point 


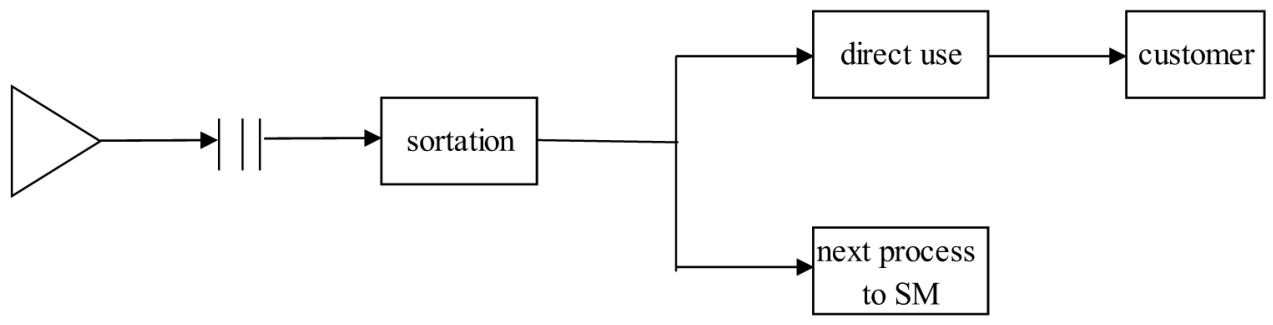

Fig. 3. Block scheme of the second extended process of sorting

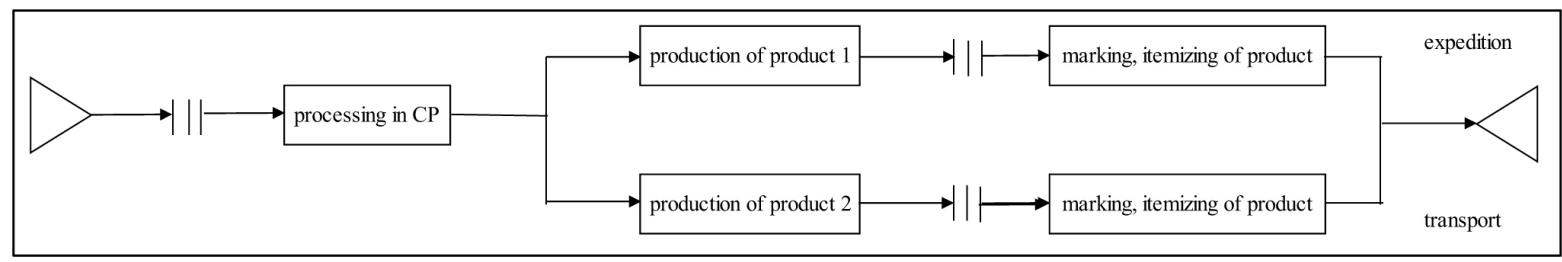

Fig. 4. Block scheme of the simplified processing process

\section{DESCRIPTION OF THE SIMULATION MODEL}

The basic area of the simulation model is the map of Slovakia (Figure 5.) with hierarchical blocks that were created by grouping blocks into 9 complex structures for clarity and total "simplification" of the proposed simulation model. Specifically, it is possible to talk about the complete structures presenting the course of processes in $\mathrm{CCP}$ in the regions of Slovakia.

It is necessary to emphasize that the processes in all CCPs are constant, the difference is only in the input quantities of wastes. The simulation model of CCP is formed by 8 parts. The first part of the model - input of material/waste and the process of initial inspection (Figure 6.) fulfils the function of specifying the amount of input material into the $\mathrm{CCP}$ and - at the same time - through the process of initial inspection there, material sorting into two groups is carried out, according the demand of suitability or unsuitability for the next process of material use (the model was designed for the ratio $10 \%$ to $90 \%$ ).

The other two parts of the simulation model of CCP (Figure 7. and 8.) present the realization of wastes storage (Store No 1) for further processing, which means ordering and processing by other independent subjects.

\section{RESULTS OF THE SIMULATION}

With the help of the created simulation model for CCP, verification of designed model of waste management was realized with an emphasis on wastes collection. This model monitored the time of simulation, the quantity of the store, capacity of vehicles for the transport process, number of CCP. The outputs of the model were presented by the planned amount of wastes collection, the quantity of transported wasted to the CCP and the output product. It is necessary to say that this model presents a very simplified design of wastes collection, because the main condition is separate collection of wastes by the commodities of wastes (for example used tires, glasses, paper, etc.), realization of the transport process from local areas to the centralized collection points and the economic indicators for the realization and formation of these types of centralized collection point constitute the most significant conditions. However, it is thus possible to demonstrate the suitable way of connecting simulation and simulation models with wastes management because it is capable of eliminating unsuitable processes, conditions and the model can simulate a real state for waste management.

\section{CONCLUSION}

The aim of the legislation of EU is mainly to reduce negative environmental impacts of wastes to human health and the environment as well as to acknowledge wastes as a source for recycling, saving primary resources in this way. In addition to the hierarchy of waste management, an environmental action program with determined pri- 


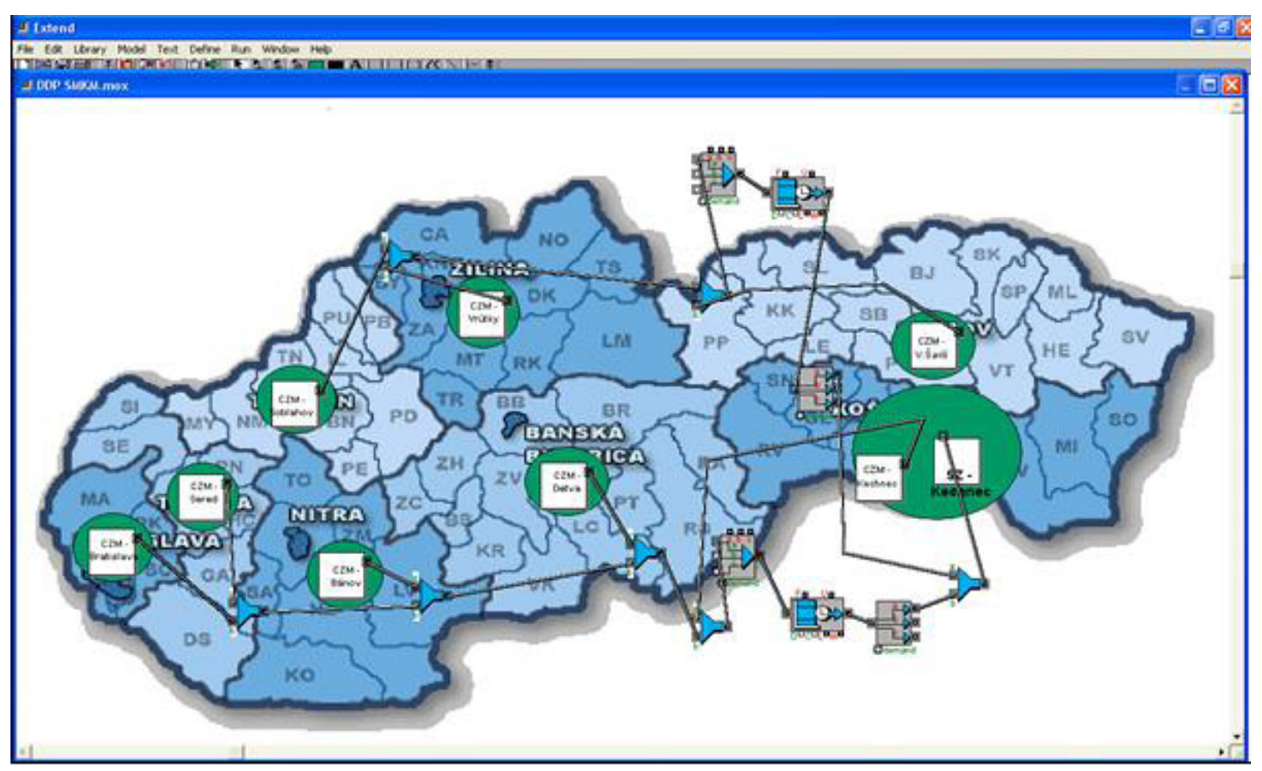

Fig. 5. The basic area of the simulation model

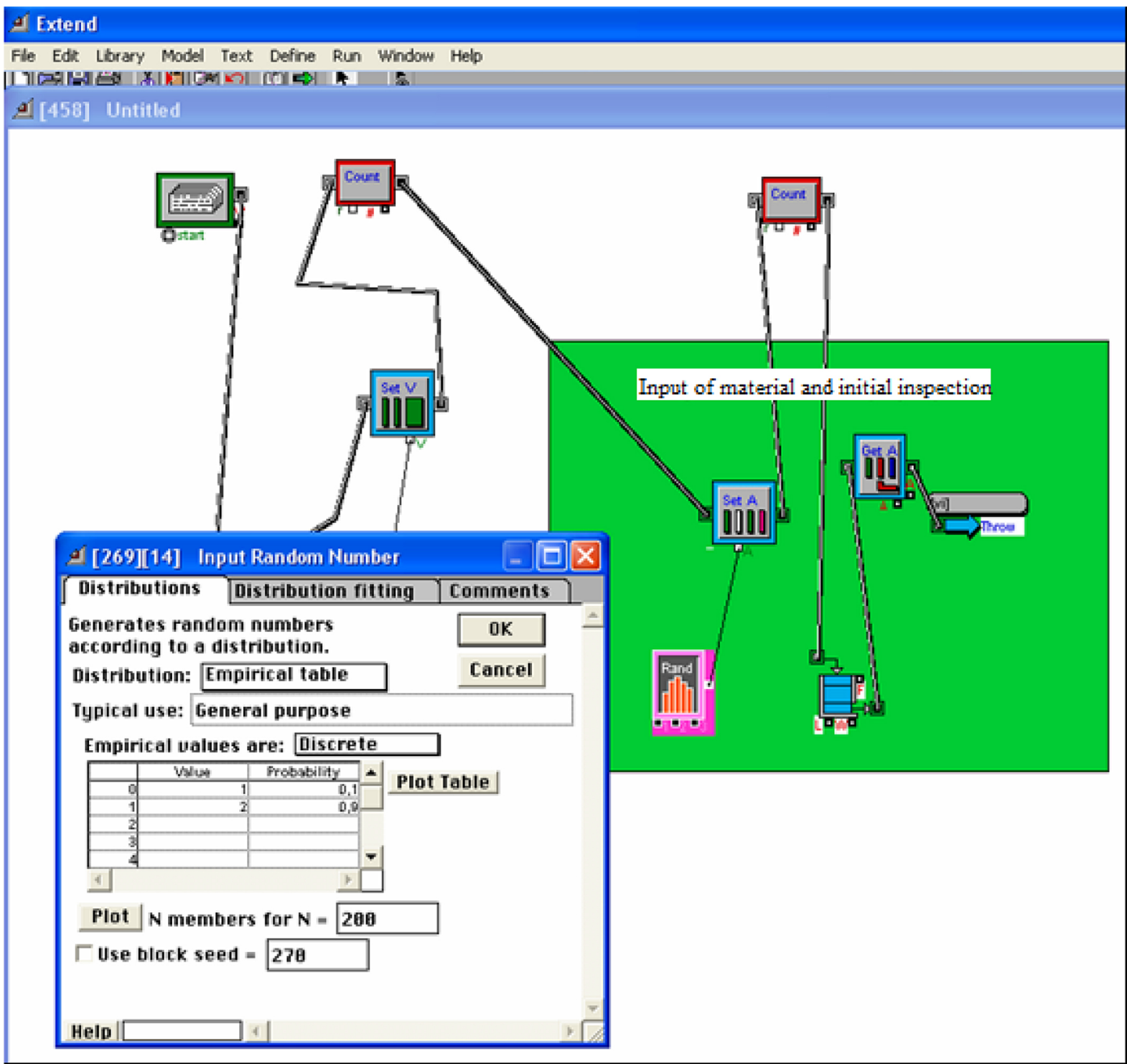

Fig. 6. The "input of wastes and the process of initial inspection" part 


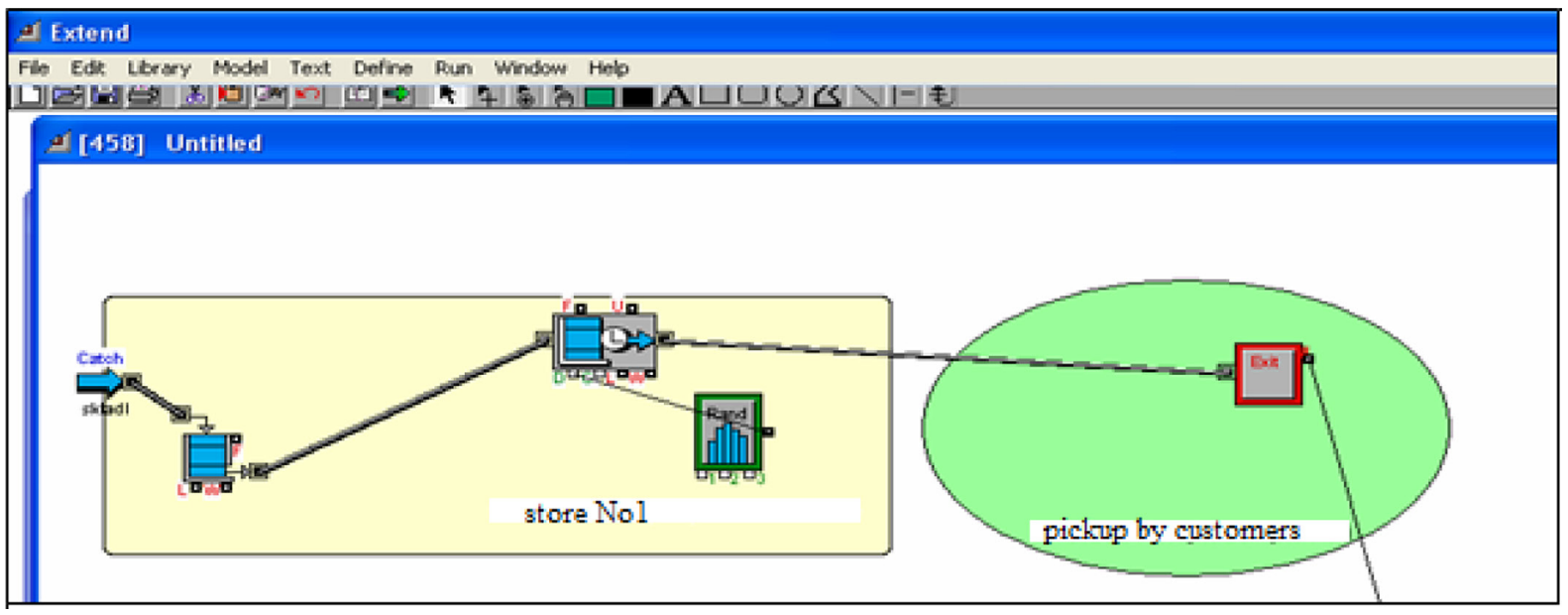

Fig. 7. The "Store No.1" part

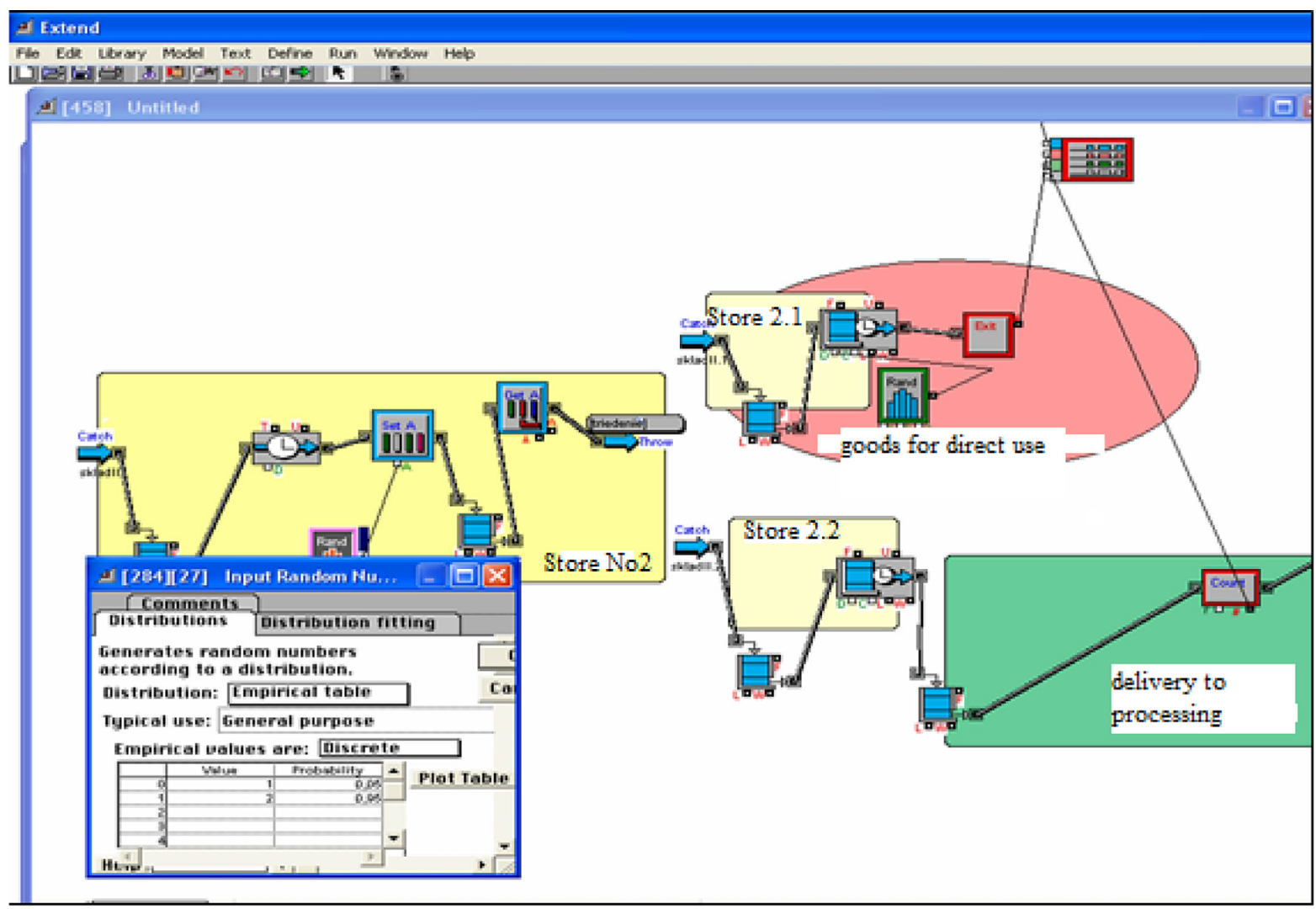

Fig. 8. The "Store No 2" part

orities for politics with wastes in EU was formed. This program mainly prefers the reduction of the volume of generated wastes, increasing the recycling and reverse use, reducing the waste incineration and dumping. The of EU program called circulation management is also very important. The aim of EU is to create so-called recycling society. This idea is enforced by EU with the help of activities for improving the products de- sign, improving the process of wastes collection at the direction of recycling and using of modern technologies for wastes treatment. This system starts with the own production of the product. It is needed to design and produce the products with the longest lifespan for use, reverse use, repairing and recycling. The aim of this program to create the circle of waste management without wastes but with reverse use of materials and resources. 


\section{Acknowledgements}

This contribution is the result of the projects VEGA 1/0403/18, VEGA 1/0063/16, KEGA 018TUKE-4/2016

\section{REFERENCES}

1. Alves, O., Passos, J., Brito, P., Goncalves, M., Monteiro, E. Characterization of municipal, construction and demolition wastes for energy production through gasification - A case study for a portuguese waste management company (Conference Paper). Lecture Notes in Electrical Engineering. Vol 505, 2018, 619-625.

2. Eckart, K., McPhee, Z., Bolisetti, T. Performance and implementation of low impact development - A review. Science of the Total Environment, 607-608, 2017, 413-432.

3. Eurostat statistics explained: Statistics of wastes [online]. 2017. [2018-3-9]. Available on $<\mathrm{http}: / /$ ec.europa.eu/eurostat/statisticsexplained/index. php/Waste_statistics /sk\#.C4.8Eal.C5.A1ie_inform.C3.Alcie_z_Eurostatu>

4. Favara, P., Gamlin, J. Utilization of waste materials, non-refined materials, and renewable energy in insitu remediation and their sustainability benefits. Journals of Environmental Management. 204, 2017, 730-737.

5. Fedorko G., Molnár V., Strohmandl J. and Vasil M. Development of Simulation Model for Light-Controlled Road Junction in the Program Technomatix Plant Simulation. Transport Means 2015 - Proceedings of the International Confer- ence. pp. 466-469, 2015.

6. Jachowicz T. and Sikora R. Methods of forecasting of the changes of polymeric products properties, Polimery 51, 2006, 177-185.

7. Lemming, G., Chambon, J.C., Binning, P.J., Bjerg, P.L. Is there an environmental benefit from remediation of a contaminated site? Combined assessments of the risk reduction and life cycle impact of remediation. Journal of Environmental Management. 112, 2012. 392-403.

8. Neradilova H. and Fedorko, G. The use of computer simulation methods to reach data for economic analysis of automated logistic systems. Open Engineering 6, 2016, $700-710$.

9. Rudawska A. and Debski, H. Experimental and numerical analysis of adhesively bonded aluminium alloy sheets joints. Eksploatacja i NiezawodnoscMaintenance and Reliability 1, 2011, 4-10.

10. Stasser, G. Computer simulation as a research tool: the discuss model of group decision making. Journal of Experimental Social Psychology. 24 (5), 1988, 393-422.

11. Wäger, P.A., Hischier, R., Eugster, M. Environmental impacts of the Swiss collection and recovery systems for waste electrical and electronic equipments. Science of the Total Environment, 409 (10), 2011, 1746-1756.

12. Zeigler, P.B., Praehoffer, H., Kim, T.G. Integrate Discrete Event and continuous complex dynamic systems. 2000, 485. ISBN 0-12-778955-1

13. Zhu, X., Wang, J., Tang, J. Recycling pricing and coordination of WEEE dual-channel closed-loop supply chain considering consumers bargaining. International Journal of Environmental Research and Public Health. 14 (12), 2017 